\title{
Implications of satellite swath width on global aerosol optical thickness statistics
}

\author{
P. R. Colarco ${ }^{1}$, L. A. Remer ${ }^{2}$, R. A. Kahn ${ }^{2}$, R. C. Levy $^{2,3}$, and E. J. Welton ${ }^{4}$ \\ ${ }^{1}$ NASA Goddard Space Flight Center, Atmospheric Chemistry and Dymamics Laboratory \\ (Code 614), USA \\ ${ }^{2}$ NASA Goddard Space Flight Center, Climate and Radiation Laboratory (Code 613), USA \\ ${ }^{3}$ Science Systems and Applications, Inc., USA \\ ${ }^{4}$ NASA Goddard Space Flight Center, Mesoscale Atmospheric Processes Laboratory \\ (Code 612), USA \\ Received: 23 March 2012 - Accepted: 2 April 2012 - Published: 12 April 2012 \\ Correspondence to: P. R. Colarco (peter.r.colarco@nasa.gov) \\ Published by Copernicus Publications on behalf of the European Geosciences Union.
}

\begin{abstract}
We assess the impact of swath width on the statistics of aerosol optical thickness (AOT) retrieved by satellite, as inferred from observations made by the Moderate Resolution Imaging Spectroradiometer (MODIS). Using collocated AERONET sun photometer ob5 servations we develop a correction to the MODIS data to account for calibration and algorithmic view angle dependency in the retrieved AOT. We sub-sample and correct the AOT data from the MODIS Aqua instrument along several candidate swaths of various widths for the years 2003-2011. We find that over ocean the global, annual mean AOT is within \pm 0.01 of the full swath AOT for all of our sub-samples. Over land,

10 however, most of our sub-samples are outside of this criterion range in the global, annual mean. Moreover, at smaller spatial and temporal scales we find wide deviation in the sub-sample AOT relative to the full swath over both land and ocean. In all, the sub-sample AOT is within \pm 0.01 of the full swath value less than $25 \%$ of the time over land, and less than $50 \%$ of the time over ocean (less than $35 \%$ for all but the widest

15 of our sub-sample swaths). These results suggest that future aerosol satellite missions having only narrow swath views may not sample the true AOT distribution sufficiently to reduce significantly the uncertainty in aerosol direct forcing of climate.
\end{abstract}

\section{Introduction}

The direct and indirect effects of aerosols are the largest uncertainties in estimates of the anthropogenic forcing of Earth's climate system (Solomon et al., 2007). Although a conceptually simpler problem than the indirect effect of aerosol on clouds, the direct effect due to scattering and absorption of radiation itself remains poorly constrained owing to uncertainty in aerosol loading, temporal and spatial distribution, and composition (Loeb and Su, 2010; Kahn, 2011). The uncertainty in anthropogenic direct aerosol radiative forcing drives much of the uncertainty in overall anthropogenic climate forcing for current climate models (Kiehl, 2007). 
Attempts to quantify aerosol properties from satellite observations have been made since the 1970s, generally with instruments not optimized for observing aerosols. Since the late 1990s a suite of satellite instruments designed to measure aerosol properties has helped refine estimates of aerosol loading and contributed some progress on re-

5 trieving other properties (e.g., absorption, particle size, shape, and vertical distribution) (see CCSP, 2009, and references therein). Despite this progress, we are left with the uncertainties summarized previously, and further refinement of the uncertainty in direct aerosol radiative forcing will require not only improved satellite measurements (for coverage and temporal sampling) but integration with in situ observations (for detailed size

10 and composition information) and transport models (for synthesis of the observational dataset) (Diner et al., 2004; Anderson et al., 2005; Kahn, 2011).

Spatial coverage is among the primary considerations for any future satellite instrument designed to measure aerosols. Given technological and budgetary constraints, a trade-off must usually be made between spatial coverage (measurement swath width)

15 and other instrument measurement characteristics, such as number of spectral and polarized channels and their accuracy, angular coverage, and pixel size. Here we assess the implications of swath width choice for sampling a single aerosol parameter - the aerosol optical thickness (AOT), a proxy for aerosol column loading. We focus on the AOT because to first order it determines the aerosol direct effect on climate. Hansen

20 et al. (1995) suggest that a change in the global mean AOT of 0.01 corresponds to a climatically important change in the global mean radiative forcing of $0.25 \mathrm{Wm}^{-2}$. If sampling artifacts introduce uncertainty in the satellite-derived global mean AOT comparable to 0.01 we will not be able to meaningfully improve estimates of aerosol direct radiative forcing.

\section{Methodology}

We use aerosol observations from the space-based Moderate Resolution Imaging Spectroradiometer (MODIS) for our study. MODIS provides near-global, daily AOT 2797

retrievals over land and ocean surfaces. There are two MODIS instruments, both in sun-synchronous polar orbits. MODIS on the Terra satellite has been operational since early 2000 and has a daytime equator crossing time of about 10:30 a.m. local time at the center of its swath. MODIS on the Aqua satellite has been operational since 5 mid-2002 and has a daytime equator crossing time of about 1:30 p.m. local time. At the nominal orbit altitude of $704 \mathrm{~km}$, the MODIS instruments observe a swath about $2300 \mathrm{~km}$ wide along their ground track. AOT is retrieved in the daytime portion of the MODIS orbit under cloud-free and glint-free conditions using separate aerosol retrieval algorithms for ocean (Tanré et al., 1996, 1997) and land (Levy et al., 2007a, b). In our

10 analysis we use the land and ocean AOT retrievals from Aqua valid at $550 \mathrm{~nm}$ from the Collection 5 MODIS algorithm products (Remer et al., 2005, 2008). The retrievals are made at $10 \times 10 \mathrm{~km}^{2}$ spatial resolution at nadir. A quality assurance (QA) flag is reported for each retrieval, indicating its level of reliability. QA flags range from 0 (lowest quality) to 3 (highest quality). In order to retain the highest quality MODIS data,

15 in what follows we use only the highest quality $(Q A=3)$ retrievals over land, and require QA > 0 over ocean (Remer et al., 2008). The uncertainty in the MODIS AOT $(\tau)$ product is characterized such that one standard deviation $(66 \%)$ of the retrievals fall within $\Delta \tau= \pm 0.03 \pm 0.05 \tau$ over the ocean and $\Delta \tau= \pm 0.05 \pm 0.15 \tau$ over land relative to the AOT measured in coincident observations from the ground-based AERONET 20 sunphotometer network (Remer et al., 2005).

Our spatial sampling strategy is illustrated in Fig. 1, which shows an example overocean scene comprising a single MODIS Aqua swath. We consider the AOT retrieved across the full swath, as well as several sub-sampled swaths in which we retain only the relevant portions of the full swath. Three swaths (M1, M2, and M3) are chosen

25 to approximate the $\sim 380 \mathrm{~km}$ wide Multi-angle Imaging Spectroradiometer (MISR, on the Terra spacecraft) swath spatial sampling. A wider "super" MISR-like swath (SM) is composed of the union of M1 and M2. To approximate the sampling of a narrow swath instrument such as the Cloud Aerosol Lidar with Orthogonal Polarization (CALIOP, aboard the CALIPSO spacecraft) we consider the samplings C1, C2, and C3, which 
are extracted at the center of the $\mathrm{M} 1, \mathrm{M} 2$, and $\mathrm{M} 3$ swaths, respectively. We emphasize that in all that follows, we are using only MODIS AOT retrievals (i.e., only the MISR-like or CALIOP-like sampling is considered; we are not using any MISR or CALIOP data in this study).

The $10 \times 10 \mathrm{~km}^{2}$ retrievals are aggregated onto a $2^{\circ} \times 2.5^{\circ}$ latitude $\times$ longitude grid, typical of a global climate model (see the grid lines in Fig. 1). The grid-averaged AOT is:

$\tau_{\text {grid }}=\frac{\sum_{i=1}^{n} \tau_{i} \cdot q_{i}}{\sum_{i=1}^{n} q_{i}}$

where $\tau_{i}$ are the 1 through $n$ individual AOT retrievals falling into the grid box and $q_{i}$

10 is the QA value assigned to each retrieval. Our aggregation is thus QA weighted. Over land we have only retained $Q A=3$ retrievals. The aggregation is performed daily. The temporally averaged AOT at a grid box is:

$\langle\tau\rangle=\frac{\sum_{j=1}^{m} \tau_{\text {grid }, j} \cdot n_{j}}{\sum_{j=1}^{m} n_{j}}$

where $\tau_{\text {grid, } j}$ is the grid average value at day $j$ from Eq. (1) and $n_{j}$ is the number of ${ }_{5}$ retrievals used to make $\tau_{\text {grid, } j}$. This aggregation and weighting strategy is the same as in Remer et al. (2008) and Colarco et al. (2010).

An important consideration we address here is what part of any observed variability in AOT across the full MODIS swath is due to instrument artifacts, either from calibration or assumptions in the aerosol retrieval algorithm. Our approach follows from

20 Levy et al. (2010). They used collocated AERONET sun photometer measurements to evaluate the Collection 5 MODIS AOT retrievals over land, finding a weak trend in the (MODIS- AERONET) AOT difference as a function of sensor zenith angle (their Fig. 10). However, this same analysis also showed that the AERONET data alone exhibit a weak trend across the same range of angles, but of opposite sign. This AERONET AOT an25 gular dependency is not an artifact, but a representation of the true AOT in different 2799

parts of the MODIS swath for this limited set of collocated points (there were 58526 MODIS Aqua and Terra collocations with AERONET used in Levy et al., 2010). We cannot at present definitively explain the reason for this trend in the AERONET collocations over land, but we suggest two possibilities. First, the full MODIS swath covers 5 a distance of $2300 \mathrm{~km}$, so the aerosols on one side of the swath are sampled from a different part of the diurnal cycle relative to their local time than are the aerosols from the other side. Alternatively, because there are large areas over which aerosol retrievals are not made - occurring primarily in the tropics (i.e., over the deserts in Saharan Africa) where the AOT is disproportionately higher than at high latitudes 10 there is possibly a latitudinal bias in the sampling used to make the AERONET-MODIS collocation dataset imprinted on the sensor view angle sorting shown in Fig. 2.

Figure 2 is similar to Levy et al. (2010) Fig. 10. It shows the sensor zenith angle dependency of both the MODIS Aqua and collocated AERONET observations of AOT over land for the period 2003-2008. Our Fig. 2 differs from Levy et al. (2010) in that 15 only MODIS Aqua observations and their respective collocated AERONET observations are used, but otherwise is derived from the same collocation database. We have 22773 collocations that have been sorted into 50 sensor zenith angle bins with an approximately equal number of observations in each bin. The results in Fig. 2 confirm the analysis in Levy et al. (2010) of (i) an approximately linear trend in the MODIS AOT as

20 a function of sensor zenith angle and (ii) an approximately linear trend - but of opposite sign - in the AERONET AOT as a function of the MODIS sensor zenith angle. The difference between these two curves is the artifact in the MODIS AOT due to view angle dependency, as best we can determine from this set of collocations, and amounts to an overall AOT statistical difference of about 0.04 across the full swath.

25 Figure 3 extends this analysis to ocean points, where we have 10407 collocations of MODIS Aqua with AERONET over the same 2003-2008 time period. We have again sorted the results by sensor zenith angle into 50 bins with approximately the same number of observations in each bin. We note that the sampling is relatively poor over a wide range of sensor zenith angles, from about $-50^{\circ}$ to $+10^{\circ}$ off nadir. This is because 
of MODIS's inability to retrieve AOT in sun glint, and so the sensor zenith angle bins are necessarily wider over this portion of the swath. Glint is not a problem over land, hence the more uniform distribution of points across sensor view angle as in Fig. 2.

Figure 3 shows that both MODIS and AERONET have a pronounced sensor view 5 angle dependency in the AOT over the ocean of nearly the same shape. We can understand this dependency if we consider more carefully how this comparison is done. MODIS does not retrieve in glint; hence AERONET observations are excluded from the glint portion of the orbit. Glint is primarily an issue at tropical latitudes, where the AOT tends to be higher in magnitude. The apparently lower AOT magnitude at near-nadir

o sensor view angles in Fig. 3 is primarily the result of collocations occurring preferentially at high latitudes in this part of the MODIS swath. There are relatively more collocation pairs at high (non-glint) sensor view angles that come from tropical latitudes. So, in the global analysis, larger view angles will tend to have larger AOT because of the predominance these tropical collocations.

15 We have superimposed on Figs. 2 and 3 our sub-sample swaths discussed previously. From the difference curves in Figs. 2 and 3 we calculate a correction term for each sub-sample, computed as the (MODIS-AERONET) difference between the averaged across the relevant sub-sample. These are summarized in Table 1, and allow us to treat the different sub-samples uniformly when making comparisons. Note that the

20 MODIS error from AERONET in all cases falls within the expected accuracy bounds described above and in the relevant literature. The correction terms are subtracted from the grid aggregated AOT described above, using the appropriate correction term for land and ocean for each sub-sample. The full swath AOT value is similarly corrected by the (MODIS-AERONET) difference. This corrected dataset is the basis of the results 25 and analysis that follow.

\section{Results}

The sub-sampled, swath-corrected MODIS Aqua data are analyzed for the years 20032011. Figure 4 shows the time series of global, annual mean AOT over both land and ocean for each of our sampling strategies. The full swath annual mean AOT varies

5 between about 0.13 and 0.14 over the ocean and about 0.16 and 0.18 over the land, similar to the multi-year analysis presented in Remer et al. (2008). To aid comparison of the sub-sample AOT to the full swath values, the grey shading in Fig. 4 shows the envelope of \pm 0.01 AOT around the full swath AOT. Over ocean the global, annual mean AOT is essentially within that \pm 0.01 AOT range of the full swath value for all sampling

10 strategies, although the difference between the individual sub-samples may be greater. Over land, however, three of the sampling strategies are completely outside this \pm 0.01 AOT envelope.

Figure 5 shows a map of the year 2010 difference in the annual mean AOT between the full swath and the C1 sub-sample. Here we chose year 2010 and the $C 1$ sub-sample

15 because $\mathrm{C} 1$ has nearly the same global, annual mean AOT as the full swath over both land and ocean that year. Despite the similarity in this global, annual statistic, it is clear from Fig. 5 that there are considerable spatial differences between the $\mathrm{C} 1$ annual mean and the corresponding full swath annual mean. For example, C1 has a greater AOT over most of the Saharan dust plume, the United States land area, and Siberia,

20 whereas the full swath has a higher annual mean AOT over the southern ocean and the North Pacific Asian pollution plume. Similar plots for the other sampling strategies (not shown here) reveal other regional variability in the differences between the full swath and sub-sample annual mean AOT.

Figure 6 shows a complementary analysis to Fig. 4 in which the climatology of 25 monthly mean AOT over the period 2003-2011 for each sampling strategy is compared. Although the sub-sample annual mean AOT over ocean is within 0.01 of the full swath annual mean AOT, there is considerable month-to-month variability, with all but one of the sub-samples deviating from the monthly mean full swath AOT by more than 
0.01 at some point during the year. Over land the deviation of the sub-sample AOT from the full swath value has an even more pronounced month-to-month variability, with all sub-samples showing deviations greater than 0.01 at some point in the annual cycle and several almost never within the \pm 0.01 AOT envelope.

Figure 7 shows the frequency distribution of the monthly mean AOT of all grid-boxes for each of our sampling strategies over the period 2003-20011. Over ocean, the most probable AOT value is about 0.1 . The sub-sample AOT distribution is most like the full swath for the wider sub-samples (i.e., for SM, M1, M2, and M3). Of the narrow swaths, $\mathrm{C} 1$ and $\mathrm{C} 2$ have nearly the same AOT distribution. There is somewhat more spread in

10 the AOT distribution for land. The most probable AOT is again about 0.1 , but the high AOT tails for all distributions are much longer than for ocean, consistent with land being the major source region of aerosols.

Figure 8 shows the cumulative frequency distribution of the difference between the indicated sub-sample and the full swath AOT. The results in Fig. 8 are summarized in

15 Table 2, which shows from Fig. 8 the fraction of subsample monthly mean AOT points within 0.01 of the corresponding full swath AOT. Over ocean the widest sub-sample swaths have the highest fraction of points within 0.01 of the full swath AOT (almost $50 \%$ for SM, between about $17-34 \%$ for the MISR-like swaths). The narrowest swaths (C1, C2, and C3) have the lowest fraction within 0.01 AOT, between about 14-20\%.

$20 \quad 4$ Discussion

The data in Figs. 2 and 3 show collocated MODIS Aqua and AERONET AOT observations sorted by the MODIS Aqua sensor view angle. The AERONET data show a view angle dependency in the AOT over both land and ocean. To the extent that AERONET is as close to a direct measurement of the column AOT that we have, this view angle

25 dependency reflects real variability in AOT across the satellite observation swath due to the aerosol spatial variability. The difference between the MODIS and AERONET data sorted this way reveals the additional view angle dependency in the MODIS AOT

2803

product due to instrument and algorithmic artifacts. The results over land (Fig. 2) are similar to what was shown in Levy et al. (2010). The results over ocean (Fig. 3) are presented here for the first time.

We use the results in Figs. 2 and 3 to construct a correction to the MODIS data as 5 a function of our sub-sample swath choices. This correction term (Table 1 ) is subtracted from our grid-aggregate MODIS AOT values in our analysis. We acknowledge potential limitations in this approach, in that (i) we did not investigate any geographical or temporal variability in these correction terms and (ii) we cannot be confident in how the actual view angle artifact in MODIS behaves away from the admittedly limited number

o of AERONET sites. Both issues amount to the limitation of data availability: there are relatively few sites and few coincidences from which to draw this collocation dataset. On the other hand, it is the only dataset we presently have suitable for this analysis.

Correcting the MODIS Aqua AOT values as described above, we see from Fig. 4 that the time series of the global, annual mean AOT over the ocean is always within \pm 0.01

15 of the full swath value for all of the sub-sample swaths. The individual sub-samples, however, may differ from each other by more than 0.01 . Over land there is considerably greater diversity among the sub-samples such that several of them (SM, M1, M2, and C3) are always or almost always different from the full swath annual mean AOT by more than 0.01. The deviation of the MODIS sub-samples from the full swath shown in Fig. 4

20 reveals the difference in the global, annual mean AOT that arises from spatial sampling considerations. Figure 6 shows that the picture is more complicated if time averages shorter than the annual mean are considered, revealing distinct seasonal patterns in the differences from the full swath for most of the sub-samples, over both ocean and land. The (sub-sample-full swath) AOT difference tends to peak over ocean in May-

25 June-July, perhaps in association with the high AOT Saharan dust plume peak. Over land the (sub-sample-full swath) AOT difference peaks in July-August-September, with a secondary peak over the Northern Hemisphere winter months, both periods corresponding to peaks in the over-land AOT magnitude. Note that our analysis examines 
absolute AOT differences rather than relative differences. Larger differences are expected for higher AOT magnitudes.

Figure 5 illustrates that the picture is also more complicated on spatial scales smaller than global. Although the C1 sub-sample illustrated has nearly the same global, annual 5 mean AOT as the full MODIS swath, there are broad regions where the sub-sample AOT differs from the full swath by more than 0.01 in the annual mean. Figures 7 and 8, which show the frequency distribution of monthly mean AOT of all grid boxes for the period 2003-2011, also contain information about the regional variability in AOT. In particular, Fig. 8 shows the cumulative frequency distribution of the pair-wise compar-

10 ison of the sub-sample and full swath AOT at individual grid-boxes. As summarized in Table 2, Fig. 8 reveals that over ocean the widest swath sub-sample (SM) agrees with the full swath AOT only about $50 \%$ of the time, and all the other sub-samples agree less than $40 \%$ of the time. Over land, the variability in aerosol distributions means that none of the sub-sample swaths agree with the full swath values more than $25 \%$ of the 15 time.

The frequency histograms in Figs. 7 and 8 and the results in Table 2 demonstrate that over ocean the broader the swath, the better the subsample matches the full swath's variability. The histograms of $\mathrm{SM}, \mathrm{M} 1, \mathrm{M} 2$ and $\mathrm{M} 3$ better match the full swath than do the histograms of $\mathrm{C} 1, \mathrm{C} 2$ and $\mathrm{C} 3$. The same point is generally true over land, al-

20 though here the M1 swath performs worse than the corresponding C1 swath and has the further effect of degrading the SM swath representation of variability. We are uncertain of the reason for this, but we note that over land - where glint is not an issue - the full swath sampling covers relatively more of the Earth than the sub-samples, whereas this is less true over the ocean. On the other hand, there are large regions of

25 the Earth where the land retrieval is never attempted (i.e., deserts) which suggest further exploration of this discrepancy be focused on regional rather than global statistics. The advantage of the broader swaths over the curtains is less apparent for the global mean, as seen in Figs. 4 and 6. Other studies that address only global means miss this important point.

2805

\section{Conclusions}

We have investigated the effects of satellite spatial sampling on the statistics of aerosol optical thickness. Our approach was to sub-sample the wide-swath MODIS Aqua observations along several candidate sub-swaths that represent MISR-like and CALIOP-

5 like viewing scenes. We employed a database of collocated MODIS and AERONET observations to investigate the sensor view angle dependencies in the MODIS AOT product. Our analysis of the AERONET data reveals that there are real view angle dependencies in the AOT across the MODIS swath - representing real variability in AOT across the swath. The results over land are similar to those shown in Levy et al. (2010).

${ }_{10}$ The results over ocean are presented here for the first time. Comparing the MODIS and AERONET view angle dependencies we develop a correction to the MODIS Aqua observations to account for the residual sensor view angle dependency due to calibration and algorithmic artifacts. We analyze the corrected MODIS Aqua observations along the full swath and our candidate sub-swaths.

15 Our results show the limitations of narrow swath instruments at capturing the variability and distribution of AOT as inferred from the full swath MODIS observations. In particular, we find that over ocean the narrow swath sub-samples are able to capture the global, annual mean AOT to within \pm 0.01 over the full swath observation. This tolerance criterion is chosen because it corresponds to approximately the change in aerosol

20 loading that must be detected in order to determine a climatically important change in aerosol direct radiative forcing of $0.25 \mathrm{Wm}^{-2}$ (Hansen et al., 1995). Over land this criterion is only met in the global, annual mean for some of the sub-sampled swaths. None of the sub-sampled swaths investigated meet the \pm 0.01 AOT relative to the full swath criterion consistently at regional or monthly time scales. Comparing individual grid box

25 aggregates of the MODIS data we find that this criterion is met only about $50 \%$ of the time over the ocean for the widest swath (SM) and between about 14-35\% of the time for the narrower swaths. Over land, none of the sub-sampled swaths meet this criterion more than about $25 \%$ of the time. 
In summary, our results show that narrow swath sampled AOT differs substantially from the full swath AOT. We also show that the position of the narrow swath within the full swath affects the results. The magnitudes of these differences are sufficient to call into question the credibility of using narrow swath or curtain, space-based aerosol

5 measurements alone to reduce the current uncertainty in aerosol direct radiative forcing of climate.

Our study demonstrates that sampling matters, and raises several questions. First, what does the full swath AOT from MODIS actually tell us about the global aerosol system? We see significant view angle dependencies in the MODIS AOT retrieval due

10 to the algorithm's avoidance of glint in the high-aerosol-loading regions of the tropics. Given this preference for cleaner high latitudes and other sampling biases, what does the global, annual average AOT derived from the full-swath MODIS observations mean? Furthermore, Levy et al. (2009) showed how strongly the choice of averaging strategy affected the monthly mean AOT derived from MODIS. We explored only one

15 such strategy here. One of the major conclusions of this work is that statistical results from even a broad swath instrument such as MODIS are subject to uncertainty introduced from sampling and aggregation issues.

The global aerosol system is temporally and spatially variable, and any reasonable sampling and aggregation method applied to observing this system will introduce sam-

20 pling biases. Simply acquiring a data set with abundant statistics does not guarantee that it will reflect the planet's mean aerosol loading and especially not its variability. The best we can do is to observe the Earth's aerosols with a combination of sensors (both satellite and sub-orbital), employing varying sampling strategies in order to monitor and correct for the deficiencies inherent in any particular strategy. The correction 25 we employ here to the MODIS data, using AERONET, is one such example, but even so, the limited collocation data set introduces its own uncertainty.

It is our hope that this study prompts further research into these and other questions related to the quality and coverage of the aerosol observing system. An extension of this work would be to explore these sampling dependencies in the context

2807

of a data-assimilation grade instance of the MODIS dataset (e.g., Zhang and Reid, 2006) that has been tuned to reduce as much as possible the MODIS AOT artifacts. A further extension would be to perform similar sampling analyses in the context of a global aerosol transport model, which could help characterize the spatial and tempo-

5 ral sampling dependencies. An optimal approach may be to formally assimilate various sub-sampled MODIS data sets into a transport model and investigate the impact on predicted aerosol distributions and radiative forcing.

Acknowledgements. This work was funded by the NASA Earth Science Division as part of the preformulation study for the Aerosol, Cloud, and ocean Ecosystem (ACE) Mission. We

10 acknowledge Hal Maring, Paula Bontempi, Mark Schoeberl, David Starr, and Lisa Callahan for supporting this work.

\section{References}

Anderson, T. L., Charlson, R. J., Bellouin, N., Boucher, O., Chin, M., Christopher, S. A., Haywood, J., Kaufman, Y. J., Kinne, S., Ogren, J. A., Remer, L. A., Takemura, T., Tanré, D.,

15 Torres, O., Trepte, C. R., Wielicki, B. A., Winker, D. M., and Yu, H. B.: An "A-Train" strategy for quantifying direct climate forcing by anthropogenic aerosols, B. Am. Meteorol. Soc., 86, 1795-1809, 2005.

CCSP (US Climate Change Science Program) Synthesis and Assessment Product 2.3: Atmospheric Aerosol Properties and Climate Impacts, edited by: Chin, M., Kahn, R., and Schwartz, S., US Climate Change Science Program, Washington, DC, USA, 116 pp., 2009.

Colarco, P., Da Silva, A., Chin, M., and Diehl, T.: Online simulations of global aerosol distributions in the NASA GEOS-4 model and comparisons to satellite and ground-based aerosol optical depth, J. Geophys. Res., 115, D14207, doi:10.1029/2009JD012820, 2010.

Diner, D. J., Ackerman, T. P., Anderson, T. L., Bösenberg, J., Braverman, A. J., Charlson, R. J., 25 Collins, W. D., Davies, R., Holben, B. N., Hostetler, C. A., Kahn, R. A., Martonchik, J. V., Menzies, R. T., Miller, M. A., Ogren, J. A., Penner, J. E., Rasch, P. J., Schwartz, S. E., Seinfeld, J. H., Stephens, G. L., Torres, O., Travis, L. D., Wielicki, B. A., and Yu, B.: PARAGON: an integrated approach for characterizing aerosol climate impacts and environmental interactions, B. Am. Meteorol. Soc., 85, 1491-1501, doi:10.1175/BAMS-85-10-1491, 2004. 
Hansen, J., Rossow, W., Carlson, B., Lacis, A., Travis, L., Del Genio, A., Fung, I., Cairns, B., Mishchenko, M., and Sato, M.: Low-cost long-term monitoring of global climate forgings and feedbacks, Clim. Change, 31, 247-271, 1995.

Kahn, R. A.: Reducing the uncertainties in direct aerosol radiative forcing, Surv. Geophys., online first: doi:10.1007/s10712-011-9153-z, 2011.

Kiehl, J. T.: Twentieth century climate model response and climate sensitivity, Geophys. Res. Lett., 34, L22710, doi:10.1029/2007GL031383, 2007.

Levy, R. C., Remer, L. A., and Dubovik, O.: Global aerosol optical properties and application to moderate resolution imaging spectroradiometer aerosol retrieval over land, J. Geophys. Res., 112, D13210, doi:10.1029/2006JD007815, 2007 a.

Levy, R. C., Remer, L. A., Mattoo, S., Vermote, E. F., and Kaufman, Y. J.: Second-generation operational algorithm: retrieval of aerosol properties over land from inversion of moderate resolution imaging spectroradiometer spectral reflectance, J. Geophys. Res., 112, D13211, doi:10.1029/2006JD007811, 2007b.

15 Levy, R. C., Leptoukh, G. G., Kahn, R., Zubko, V., Gopalan, A., and Rember, L. A.: A critical look at deriving monthly aerosol optical depth from satellite data, IEEE T. Geosci. Remote Sens., 47, 2942-2956, doi:10.1109/TGRS.2009.2013842, 2009.

Levy, R. C., Remer, L. A., Kleidman, R. G., Mattoo, S., Ichoku, C., Kahn, R., and Eck, T. F.: Global evaluation of the Collection 5 MODIS dark-target aerosol products over land, Atmos. Chem. Phys., 10, 10399-10420, doi:10.5194/acp-10-10399-2010, 2010.

Loeb, N. G. and Su, W.: Direct aerosol radiative forcing uncertainty based on a radiative perturbation analysis, J. Climate, 23, 5288-5293, doi:10.1175/2010JCLI3543.1, 2010.

Mishchenko, M. I., Cairns, B., Hansen, J. E., Travis, L. D., Burg, R., Kaufman, Y. J., Martins, J. V., and Shettle, E. P.: Monitoring of aerosol forcing of climate from space: analysis of measurement requirements, J. Quant. Spectosc. Ra., 88, 149-161, doi:10.1016/j.jqsrt.2004.03.030, 2004.

Remer, L. A., Kaufman, Y. J., Tanré, D., Mattoo, S., Chu, D. A., Martins, J. V., Li, R.-R., Ichoku, C., Levy, R. C., Kleidman, R. G., Eck, T., Vermote, E., and Holben, B. N.: The MODIS aerosol algorithm, products, and validation, J. Atmos. Sci., 62, 947-973, 2005.

30 Remer, L. A., Kleidman, R. G., Levy, R. C., Kaufman, Y. J., Tanré, D., Mattoo, S., Martins, J. V., Ichoku, C., Koren, I., Yu, H., and Holben, B. N.: Global aerosol climatology from the MODIS satellite sensors, J. Geophys. Res., 113, D14S07, doi:10.1029/2007JD009661, 2008.

2809

Solomon, S., Qin, D., Manning, M., Marquis, M., Averyt, K., Tignor, M. M. B., Miller Jr., H. L., and Chen, Z.: Climate Change 2007: The Physical Sciences Basis, Cambridge University Press, Cambridge, United Kingdom and New York, NY, USA, 996 pp., 2007.

Tanre, D., Herman, M., and Kaufman, Y.: Information on aerosol size distribution contained in solar reflected spectral radiances, J. Geophys. Res., 101, 19043-19060, 1996.

Tanre, D., Kaufman, Y., Herman, M., and Mattoo, S.: Remote sensing of aerosol properties over oceans using the MODIS/EOS spectral radiances, J. Geophys. Res., 102, 16971-16988, 1997.

Zhang, J. and Reid, J. S.: MODIS aerosol product analysis for data assimilation: assessment of over-ocean level 2 aerosol optical thickness retrievals, J. Geophys. Res., 111, D22207, doi:10.1029/2005JD006898, 2006. 
Table 1. Error in MODIS Aqua data for each sub-sample due to calibration of algorithmic angular artifacts. These values are subtracted from the grid aggregate values of the MODIS dataset in order to correct for angular artifacts.

\begin{tabular}{lrr}
\hline & Ocean & Land \\
\hline Full swath & 0.0044 & -0.0023 \\
SM & -0.0027 & -0.0229 \\
M1 & -0.0006 & -0.0298 \\
M2 & -0.0049 & -0.0168 \\
M3 & 0.0208 & 0.0056 \\
C1 & -0.0001 & -0.0268 \\
C2 & 0.0026 & -0.0095 \\
C3 & 0.0177 & 0.0168 \\
\hline
\end{tabular}

2811

Table 2. MODIS Aqua fraction of sampled, grid averaged AOT values within \pm 0.01 of full swath MODIS Terra AOT for the period 2003-2011.

\begin{tabular}{rrr}
\hline & Ocean & Land \\
\hline SM & 0.443 & 0.145 \\
M1 & 0.246 & 0.115 \\
M2 & 0.339 & 0.202 \\
M3 & 0.164 & 0.234 \\
C1 & 0.182 & 0.120 \\
C2 & 0.200 & 0.162 \\
C3 & 0.138 & 0.118 \\
\hline
\end{tabular}




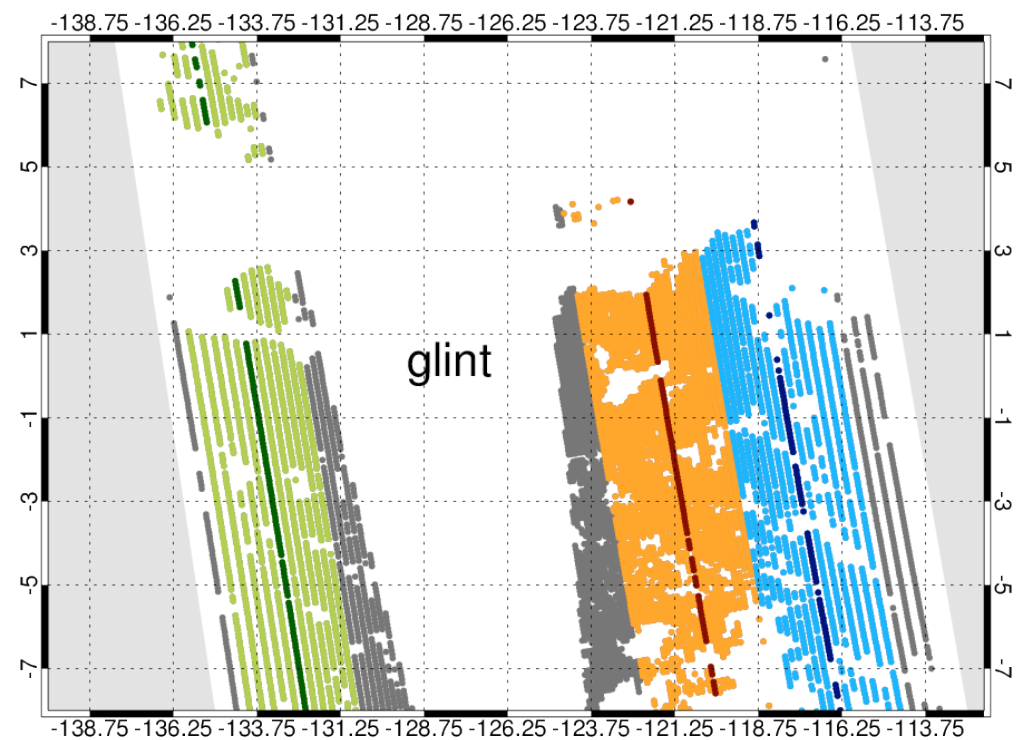

Fig. 1. Example of spatial coverage of the MODIS Aqua instrument for an ocean region on 5 June 2010. The shaded dots indicate the locations of the MODIS AOT retrievals, with the grey dots indicating the full MODIS swath (MO). Overlaid on the grey dots are different colors for our various sampling strategies $(\mathrm{M} 1=$ light blue, $\mathrm{M} 2=$ orange, $\mathrm{M} 3=$ green, $\mathrm{C} 1=$ deep purple, C2 = deep red, C3 = deep green, and SM = combined M1 and M2 swath). The light-grey areas on the left and right side of the figure are outside the swath, while the central white region (labeled "glint") is where no aerosol retrievals are made due to sunglint. Remaining patchy white areas are where aerosol retrievals were not made due to clouds. We have superimposed the grid lines of our $2^{\circ} \times 2.5^{\circ}$ latitude $\times$ longitude spatial aggregation grid.
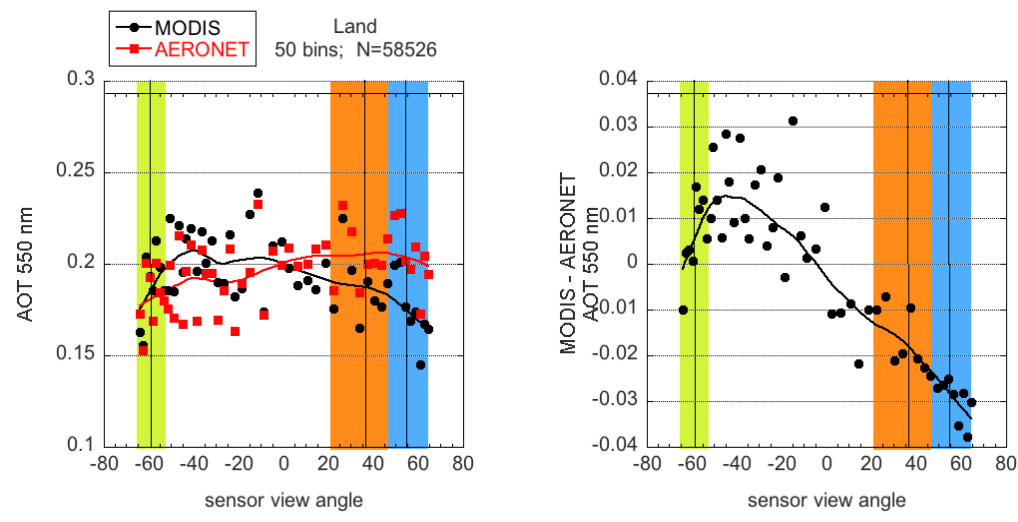

Fig. 2. Collocated MODIS Aqua (black) and AERONET (red) over land AOT observations during the period 2003-2008, sorted as a function of the MODIS sensor view angle (left). Also shown is the difference MODIS-AERONET (right). On each panel we have indicated the sub-sample swath locations used in our study (colors similar to Fig. 1). 

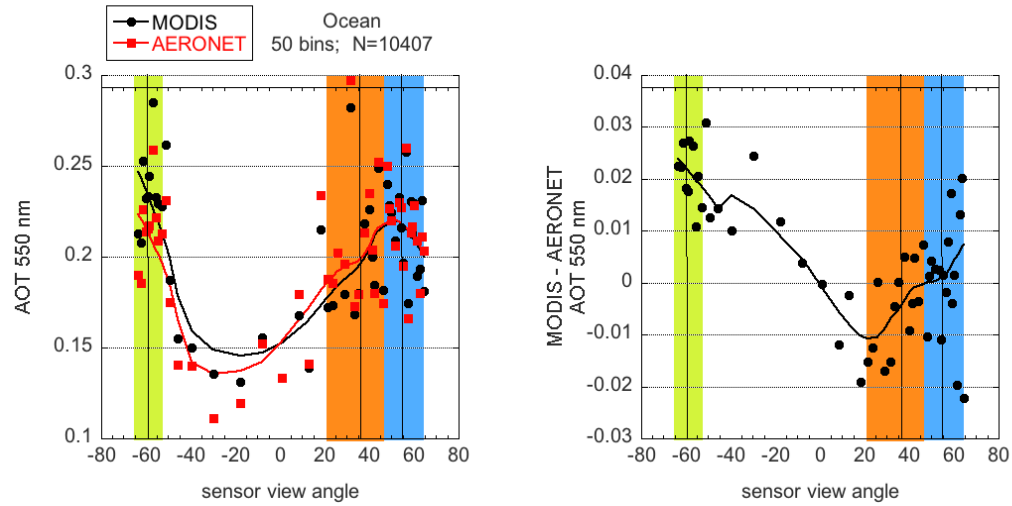

Fig. 3. Collocated MODIS Aqua (black) and AERONET (red) over ocean AOT observations during the period 2003-2008, sorted as a function of the MODIS sensor view angle (left). Also shown is the difference MODIS-AERONET (right). On each panel we have indicated the subsample swath locations used in our study (colors similar to Fig. 1).
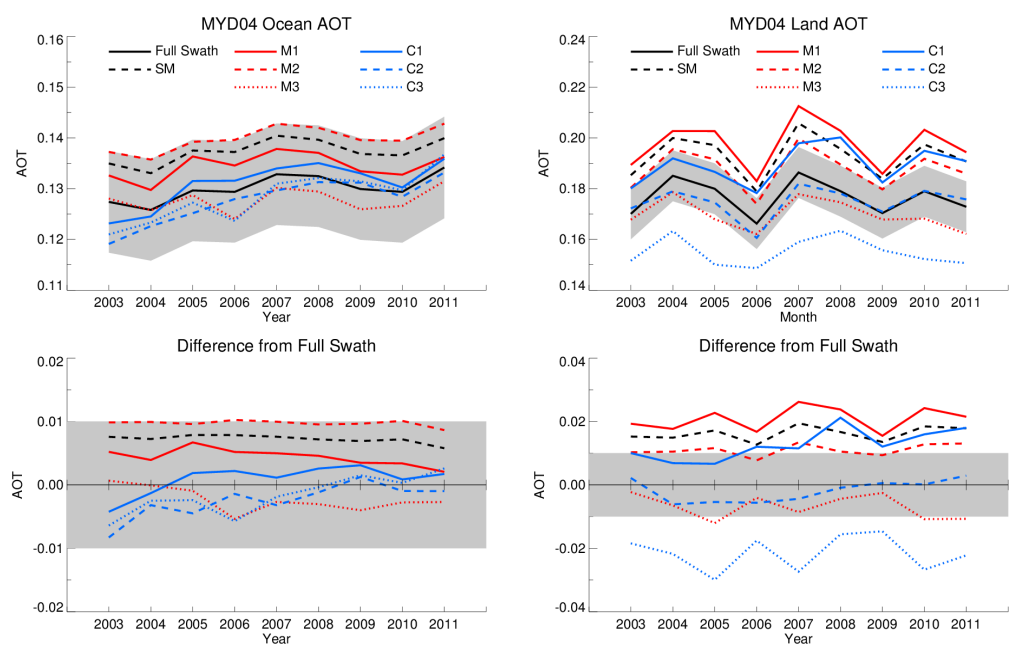

Fig. 4. Time series of the annual mean MODIS Aqua AOT over ocean (left) and land (right). The full swath AOT is indicated by the solid black line, with the grey shading showing \pm 0.01 AOT of the full swath mean value. The bottom panel in each is the difference of the sub-sampled average from the full swath average. 

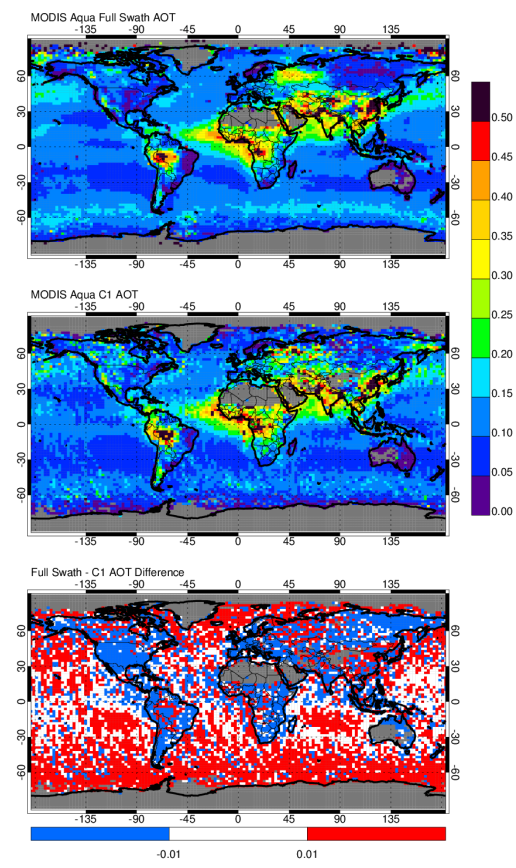

Fig. 5. Year 2010 annual mean AOT for the MODIS Aqua full swath (top) and C1 sub-sample (middle). The bottom panel shows the difference (Full Swath - C1).

2817
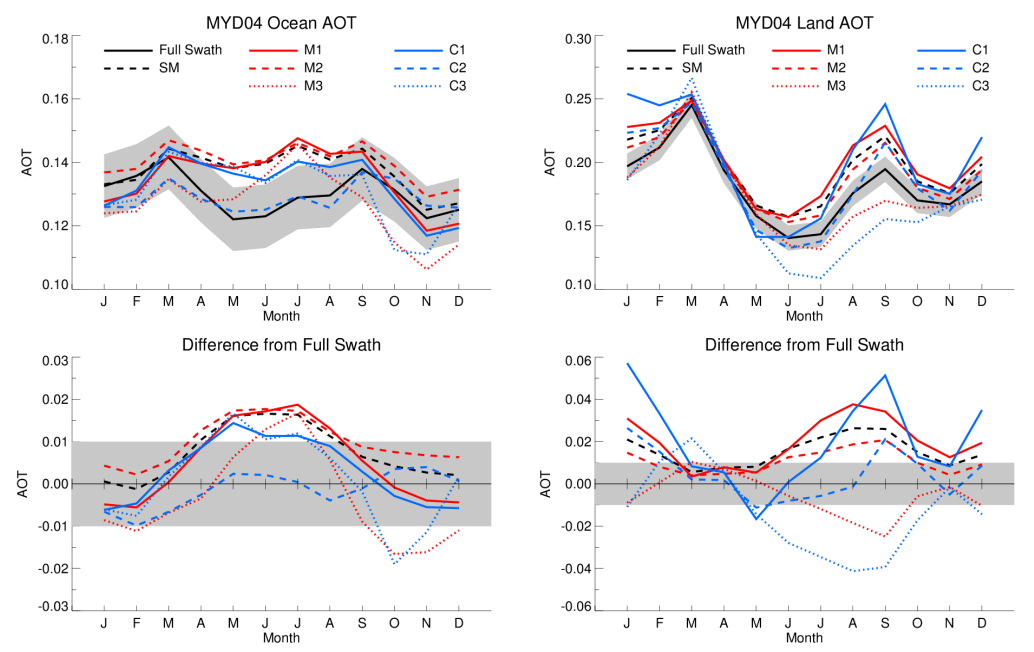

Fig. 6. Climatology of the MODIS Aqua monthly mean AOT over ocean (left) and land (right) for the period 2003-2011. The full swath AOT is indicated by the solid black line, with the grey shading showing \pm 0.01 AOT of the full swath mean value. The colors indicate the MISR-like (red) and CALIOP-like (blue) sub-sampling, and the line style indicates the particular position in the full swath: solid $=(M 1, C 1)$, dashed $=(M 2, C 2)$, and dotted $=(M 3, C 3)$. The dashed black line is the SM sample. The bottom panel in each is the difference of the sub-sampled average from the full swath average. 

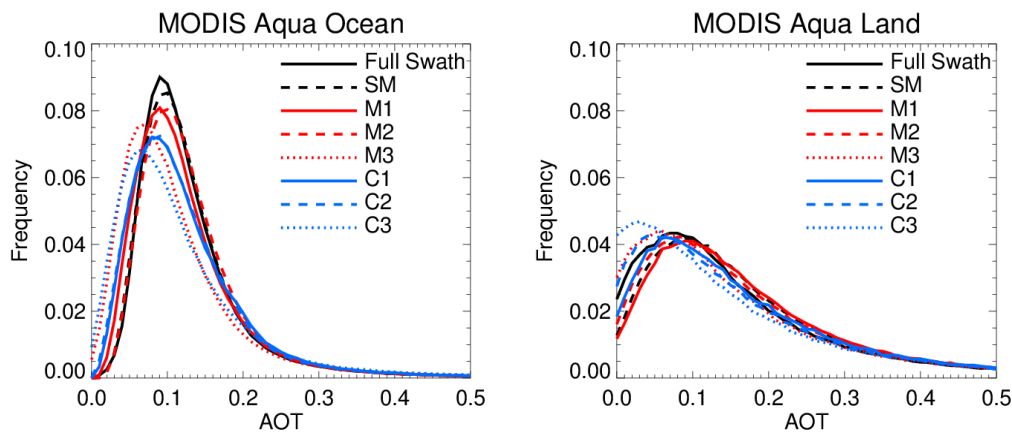

Fig. 7. MODIS Aqua years 2003-2011 frequency distribution of monthly mean AOT values from over ocean (left) and land (right) for each sampling strategy.
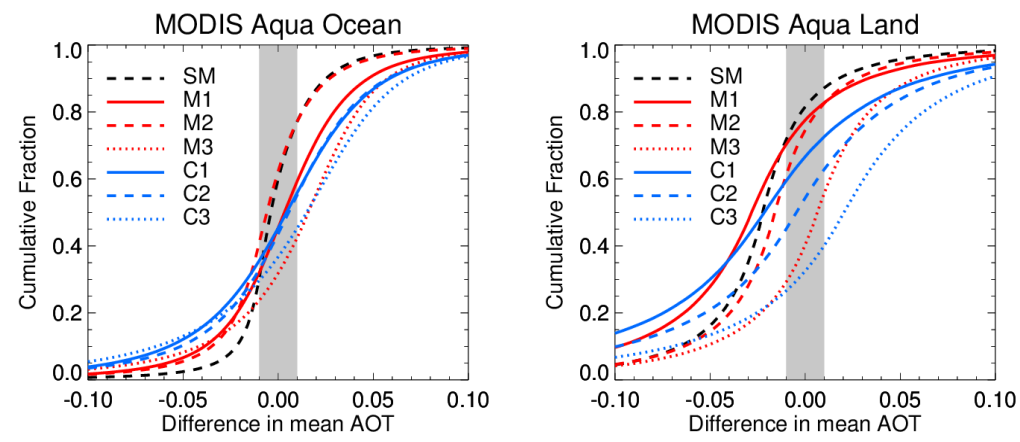

Fig. 8. MODIS Aqua years 2003-2011 cumulative difference distribution of AOT from full swath AOT over ocean (left) and land (right) for each sampling strategy. 